\title{
Microbial Intimacy
}

\section{Andrew Dawson and Simone Dennis}

\begin{abstract}
АвsтRAct: In this article, we highlight how COVID-19 has transformed, is transforming and may transform into the future human intimacies. This, we argue, is an appropriate focus for anthropological investigation particularly. We posit a scaler approach to the anthropological study of the transformation of intimacy in COVID-19, embracing multiple levels from human relations with microbes through to human relations with deities. Furthermore, we offer examples of the overlaps between the ways in which intimate relationships at small and large scales are conceptualised, especially metaphorically.
\end{abstract}

KeYwords: anthropology, bodies, COVID-19, intimacy, microbes, pandemic

Lest we need reminding, coronavirus 2019 (COVID-19) is an infectious disease of zoonic origin caused by severe acute respiratory syndrome coronavirus 2 (SARS$\mathrm{CoV}-2)$. A disease of the lungs and respiratory system primarily, it affects the kidneys, heart and cardiovascular system too.

COVID-19 is highly contagious, and considerably more so than influenza. Initially identified in December 2019 in Wuhan in the Hubei province of China, by 11 March 2020 the World Health Organization (WHO) had declared a COVID-19 pandemic. At the time of writing in September 2020, the WHO reported that there was no proven vaccine and there were over 33 million cases globally. And, with no proven treatments at hand either, it said that there were over 1 million deaths caused by the disease (WHO 2020). Furthermore, even those who recover from the disease may remain affected. Patients who have recovered from the acute phase of the disease have experienced in 'long COVID' a range of symptoms, including fatigue, memory loss, fever, breathlessness and even blindness, and it is now recognised that COVID-19 can cause long-term damage to organs, especially the lungs and heart.

The social as well as the health impacts of the COVID-19 pandemic are proving to be epochal in magnitude. Notably, the economic impacts have been massive, with supply shortages, a crash of the global stock market akin to that in the global financial crisis, the GFC, of 2007-2009, a recession, rising unemployment and a dramatic decline in household economic well-being. For example, The International Labour Organisation estimated that by June 2020400 million jobs would be lost globally since the beginning of the pandemic. Likewise, household income would diminish by 10 per cent, the equivalent of $\$ 3.5$ trillion (McKeever 2020).

However, perhaps no less significant than these kinds of macro(-economic) changes are those brought by COVID-19 to the apparent minutiae of our everyday social lives. For example, as Cynthia Sear wonders in this issue: 'Will we ever shake hands again?' Such ponderings and fears surrounding intimacy stem from the very nature of COVID-19 itself. It may be transmitted through touching contaminated surfaces. However, above all it is transmitted as droplets or aerosols emitted by carriers when they breathe, cough, sneeze or talk. Hence, besides hygiene measures such as frequent hand-washing and maskwearing, prevention has focussed largely on different forms of social distancing, including the physical distancing of people, quarantining, isolation and, of course, avoiding human touch altogether.

And, more than a broadly anti-social disease, COVID-19 impacts our intimate interpersonal relations especially severely, for the risk of infection is

Anthropology in Action, 27, no. 2 (Summer 2020): 1-8 (C) Berghahn Books and the Association for Anthropology in Action ISSN 0967-201X (Print) ISSN 1752-2285 (Online) doi:10.3167/aia.2020.270201 
greatest in situations of close social proximity, in situations of privacy (such as indoors) and in situations involving the greatest likelihood of touch. Thus, arguably, the greatest risk lies in our relationships with those with whom we are most intimate, the people we might normally turn to for care in times of illness and for the fulfilment of other needs in times of crisis. Finally, and insidiously, since carriers can be asymptomatic COVID-19 holds the potential of eroding not just contact but also trust, a fundamental precondition for most intimate relations.

\section{Anthropology and Intimacy: A Multi-Scaler Approach}

These matters of intimacy are, of course, a proper focus of anthropology. As we have defined it elsewhere, anthropology is, above all, 'an approach to social and cultural research involving long-term immersion in research contexts and the deployment of a range of methodological strategies and techniques selected by the researcher as she deems them to be contextually and interpersonally appropriate, but in which participant observation predominates' (Goodwin-Hawkins and Dawson 2018: 270). This renders our relationships with informants particularly intimate and our discipline an intimate one per se (Goodwin-Hawkins and Dawson 2018).

Appositely then, this three-issue set of Anthropology in Action considers intimacy and how it has been, is being and may be transformed by COVID-19. However, its focus extends beyond what might conventionally be regarded as the normal realm of intimacy, interpersonal relations. To bracket that off would, we argue, be inappropriate. Again, the handshake is usefully illustrative. Just as it may be a gesture of intimacy between persons, so too may it symbolise intimacies experienced at different scales. It may, for example, function as a metaphor that concretises (Lakoff and Johnson 1980) the kinds of intimacies (that are often hard to think of as intimacies) experienced between abstract entities such as nations (Anderson 2006). Writing from our current national base, where in the context of COVID-19 we have witnessed the once intimate relations between Australia and China transform into near outright hostility, and their erstwhile shaking hands transformed into symbolic clenched fists (MacDonald 2020), we are acutely aware of that.

Following this, the logic of these three special issues is broadly scaler. Volume 27, Issue 2 (this issue), entitled 'COVID-19 and the Transformation of Intimacy: Microbes - Bodies', considers how our intimate relationships with microbes and bodies, including those of others and our own, are transforming. Volume 27, Issue 3, entitled 'COVID-19 and the Transformation of Intimacy: Lovers - Deities', considers how intimate relationships between familiars such as lovers and family members, and between less obvious familiars such as citizens and states, nations and other nations, and people and gods, are transforming. Finally, and sliding back down the scales, Volume 28, Issue 1, entitled, 'COVID-19 and the Tansformation of Intimacy: Workers', considers a predominant concern within the article submissions we received, which is how intimate relations within workplaces are transforming. Reflecting the abovementioned economic impact of COVID-19 and the need for states the world over to chart a course that balances the saving of lives against the saving of livelihoods, that concern is perhaps inevitable.

These special issues contain 49 articles - shorter articles of between 2,500 and 4,000 words and feature articles of between 5,000 and 8,000 words - by 69 researchers reflecting on COVID-19 and how it is transforming intimate relations in 23 different countries, and sometimes between countries. For readers interested is specific areas, we provide a guide here:

- Australia: Bell (Volume 28, Issue 1); Dawson $(27,3)$; Décobert $(27,3)$; Fergie et al. $(27,2)$; McKenzie (27,3); Roth et al. $(28,1)$; Sear $(27,2)$; Vokes and Atukunda $(28,1)$.

- Austria: Arantes (27,2); Hamm $(27,3)$; Streinzer et al. $(27,2)$.

- Brazil: Parreiras $(28,1)$.

- China: Chen $(27,2)$; Luo $(27,3)$.

- Denmark: McGahey $(28,1)$; Ulfstjerne $(27,2)$.

- England: Andrews $(27,2) ;$ Baffelli and Schröer $(28,1)$; Dawson $(27,3)$; Dreissan et al. $(28,1)$; Hamm (27,3); Lim (27,2); McLeod (27,2); Pink et al. $(27,3)$; Simpson $(27,3)$; Skinner $(27,2)$.

- France: Lennes $(28,1)$.

- Germany: Baffelli and Schröer $(28,1)$; Streinzer et al. $(27,2)$.

- India: Chatopaddhyay $(28,1)$; Ghosh $(28,1)$; Satyogi $(28,1)$.

- Italy: Hamm $(27,3)$; Messineo $(27,2)$.

- Pakistan: Malik $(27,3)$.

- Peru: Irons $(27,3)$.

- Republic of Ireland: Drazkiewicz $(27,3)$; Whyte $(27,3)$.

- Russia: Kurnosov and Varfolomeeva $(27,2)$; Ragozina $(27,3)$. 
- Scotland: Douglas $(28,1) ;$ McNeilly and Reece $(27,3)$; Simpson $(27,3)$.

- Spain: Andrews $(27,2)$.

- Switzerland: Streinzer et al. $(27,2)$.

- Thailand: Herzfeld $(27,3)$.

- Turkey: Kaptan $(27,3)$.

- Uganda: Vokes and Atakunda $(28,1)$.

- United States: Bell $(28,1)$; Block $(27,2)$; Casteneda and Searcy $(28,1)$; Colas $(27,2)$; Herzfeld $(27,3)$.

- Vietnam: Ngoc Bich et al. $(28,1)$; Nguyen $(27,3)$.

- Wales: Goodwin-Hawkins $(27,3)$.

We believe that this is the first major anthropological survey of the COVID-19 pandemic. However, the nature of this survey requires some definition. Many of the articles are conventional ethnographies that engage directly with informants 'in the field'. However, and inevitably because of the conditions of lockdown faced by many of the contributors, a good many of the articles are auto-ethnographies, 'netnographic' studies (Kozinets 1998), or studies based on secondary data. This is, we believe, to the special issues' advantage. For example, and besides providing important knowledge on COVID-19 and the transformation of intimacy, it has resulted in contributions that take forward anthropological practices in other ways. It takes forward anthropology's engagement with communications technologies in studying, as Richard Vokes and Gertrude Atukunda describe it in Volume 28, Issue 1 , the 'Zoomiverse' to which so many of us have now become accustomed during lockdown and which is likely to continue framing so much of our intimate social lives in the future. And, because of tackling such an important issue as COVID-19, the reflexivity deployed in the auto-ethnographies is consistently socially revealing rather than narcissistic (Van Mannen 2011). Lastly, reflecting an often forgotten anthropological raison d'être, several of the contributions are highly comparative in focus. In short, it becomes clear, COVID-19 is transforming the ways we practise anthropology too, and the contributions in these special issues are exemplary in this regard.

\section{Beginnings}

This first issue amongst the special issues considers, as stated, how our intimate relationships with microbes and bodies, including those of others and our own, are transforming. However, and by way of an introduction, in the section subtitled 'Beginnings' three extremely important articles take us back to first experiences of COVID-19.
In the opening article, Junjie Chen provides an account of local residents' stories of the earliest of lockdowns in urban China. A process organised largely by local neighbourhood officers, its effects on the intimate lives of people reflected broader processes of post-socialist transformation and, in particular the embedding of class relations. In rich detail, Chen describes what he labels as 'graduated intimacies', with wealth and state connectedness determining the extent to which one may maintain intimate relations, especially those involving care and filial piety $(x i a o s h u)$. The practice of filial piety is culturally very significant - a source of virtue, a means of fulfilling social and moral obligations, and a route to spiritual transcendence. Lockdown has made apparent how these are becoming, increasingly potentials that are unevenly distributed.

In contrast to Chen's focus on the containment of the spread of COVID-19, the next two and, it must be said, remarkable articles focus on disease treatment and in particular on transformations of intimacy in doctor-patient relations. Both are in part autoethnographic. Kelly Colas, who is both an anthropologist and a resident physician, draws on her internal medicine resident physician experiences working in the COVID-19 intensive care unit and the COVID-19 wards and as a resident admitting COVID-19 patients during the peak of the pandemic in a hospital in Washington, DC. In contrast, Dmitry Kurnosov and Anna Varfolomeeva were amongst the first dozen confirmed COVID-19 cases in a large region of Siberia. Their article draws on their experiences there of hospitalisation and treatment.

Colas begins by noting that, of course, the biomedical encounter is historically characterised by the assumed expertise of the physician and a unilateral transfer of knowledge from physician to patient. However, lack of knowledge about and uncertainty surrounding COVID-19 refigures the doctor-patient relationship. As a result of physicians' uncertainty about disease presentation and diagnostic modalities, patients' histories and descriptions of their experiences gain increasing importance as a source of knowledge about COVID-19 for clinicians. Crucially, Colas observes, while this results often in distrust of the clinician amongst family members (who demand an expertise that is, in this case, lacking), the doctor-patient relationship in COVID-19 becomes atypically intimate as it is characterised by greater transparency.

Kurnosov's and Varfolomeeva's experiences could barely have been more different. Living with COVID19 's uncertainties might be, as it is so frequently rep- 
resented, a 'new normal' or 'COVID normal' (Liberman 2020). Within this new context, and as the case described by Colas exemplifies, the relationships between patients, doctors, medical systems and even broader institutional systems might be transformed in less alienating ways. However, Kurnosov and Varfolomeeva's near-Orwellian description of their hospitalisation experiences suggest otherwise. For example, describing their feelings of being watched by a curious medical gaze they state: 'Just as the corridor glass in our hospital rooms looked like a window to the outside world ', it 'in fact represented an extension and intensification of the surveillance mode'. Rather than heralding a new normal, Kurnosov and Varfolomeeva suggest that the uncertainties wrought by the pandemic and the lack of medical knowledge about COVID-19 make for a 'not-so-new normal' in which the disease affords a situation where patients are 'subject to near absolute state discretion', and where intimacies between doctors and patients are strictly regulated or absent.

Put together, the articles by Chen, Colas, and Kurnosov and Varfolomeeva shed important comparative light - in these cases between China, the United States and Russia - on how state systems of disease control and treatment are implicated in the regulation of populations in general (see also Foucault 1995) and the regulation of intimacies in particular.

\section{Microbes}

The contributors to the section subtitled 'Microbes and Particulates' each speculate and theorise how virus configurations meet with the most ordinary of technologies, practices and environs. Life at various scales materialises in bread-making, dealing with absences and longings, being with and dwelling in the domestic home, and encountering anew the air that is normally so backgrounded as to be wholly disattended.

As Carmen McLeod and colleagues note, 'humans and microbes have always been on intimate terms ... [now] the idea of microbes as antagonists is re-emerging with a vengeance in the way people are dealing, and told to deal, with COVID-19, where war metaphors have become, yet again, a common currency in text and talk'.

They worry about the re-emergence of an extremely adversarial understanding of microbes that may impact our capacity to live well with and successfully alongside COVID-19, should it stick around. What would it mean to have antagonistic, combative and belligerent relations with COVID-19? Would the nuanced view that sees our relations with microbes as multifaceted be eliminated in the sweep of a bleachinfused cloth? What conceptual, ecological, medical and practical consequences would the death of friendly relations have? As McLeod and colleagues note, the consequences of hygienic thinking of particular orders and registers have been demonstrated in farming contexts and in the setting of the hospital, but in the home new regimes of defensive cleaning are impacting taxonomic thinking.

McLeod and colleagues' provocation invites us to think about the consequences of metaphoric language that consequentially shapes our dealings with viruses - and a wide range of other beings, circumstances and taxonomies of the world. This might include our relations with animals and our conceptualisations of clean and dirty, inside and outside, right and wrong, and certainly life and death. Their article also, for us, raises a further question about the ways in which the virus itself engages in intimate relations of its own.

Ten years before the emergence of COVID-19, nobody would have said, for example, that bacteria have extremely sophisticated immune systems that detect and destroy invading viruses. This immune response is called CRISPR, an acronym that stands for Clustered Regularly Interspaced Short Palindromic Repeats. Confirmation of that discovery in 2007 permitted insight into the life of viruses and bacteria as they engaged one another in direct combat. The metaphoric language was not only one of generalised attack and defence, but also one of hand-to-hand combat, deception and even espionage. In a paper published in Molecular Cell in March 2019, Mary Clare Rollins and colleagues reported their discovery that viruses are 'resourceful', are able to do things like steal and repurpose bacterial defences to jam CRISPR alert signals, and engage in creative, strategic moves to evade host detection. The discovery led the authors to accord a purposeful, substantive life to viruses, who, in their terms, were 'brilliant', 'devious' and 'subversive' in their conduct of their own microscopic wars. Such notions, as McLeod and colleagues note, occasion and entail critical examination 'for their political, social and psychological implications'.

The articles in this section share in common an intention to understand the networked relations between the microscopic and the macroscopic (perhaps even the macrocosmic, in the sense that whole worlds might come available to imaginations, just as the whole world has been re-arranged, as a result of the emergence of a microscopic virus). Such is the 
range expressed in Lydia Arantes' contribution regarding bread-making. From the tiny air bubbles that emerge from the work of the micro-organisms that dwell in sourdough cultures (cultivated at home during lockdown) to much larger explorations of family, domestic space and practices of recording life in the time of COVID-19, microbes are revealed to be contexts for new practices, thoughts and reflections. The incorporation of microbial processes yield the bread that contains and creates homeliness and familiarity and that produces commensal, sensory and temporal comforts that make life seem possible, even pleasurable, in a COVID-19 context. One kind of microscopic entity not only creates the conditions for reclaiming anew the largeness of life, it also operates in tandem with another microscopic entity. Where COVID-19 microbes operate as key figures in new scientific illness (biological and social) enquiries, their yeasty contemporaries serve as the origins of life, change and promise.

Yeasts, like viruses, require special conditions to thrive and make good on their capacities to become more than themselves, to become bread. As any baker - especially a baker of sourdough - knows, careful, precise steps must be taken to coax the starter culture into bread. If any one of those conditions is not quite met, disaster ensues and bread fails to result. Viruses are similar, in that they have many conditions to meet before they can achieve their full potentials. Coronavirus first had to mutate and come into contact with a human host. It had to defeat the robust, on-guard human immune system, which is no mean feat. Then, it had to find a matching receptor cell to which it could bind, replicate, and shed itself in order to transmit. Many of these conditions are required of any virus, but the emergence of coronavirus and its accomplishment of pandemic status required even more underlying conditions to be in place for its success, not the least of which were the drawing together of human and animal worlds and human operation in the interstitial spaces between formal markets and forests, local foodways and international moral expectations. Just as it is the case with bread-making, if any step is missed in the virus' development, or any condition less than optimal, it will remain in a state of 'un-potential', just a mess of insignificant proteins. The entwinement of two nanoparticles in domestic life and the fruition of both to their full potentials demonstrates the fertility of each for thinking and living, especially when they are considered in tandem.

The entwinement of two crises, bushfire and COVID-19 as described by Deane Fergie and col- leagues, gives us leave to consider how we might critically regard and re-engage the theorising of crises - presently, that is almost always in the singular. The arrival of fire in south-eastern Australia at the same time as COVID-19 rendered the air replete with microscopic particles that made it thickly visible. Into its choking cloudiness, an invisible virus arrived. The contaminated air drove people to seek out breathable air - often amongst the company of others who were not their own kin. But the arrival of COVID-19 revealed the danger of so doing, cleaving intergenerational households apart. Comingled breath is central not only to intimacies that were bounded off when COVID-19 arrived, the conditions for and of breathing must not be taken for granted in this crisis. As Marsha Rosegarten has observed:

COVID-19 has the capacity to take our breath away, the very essence of what is necessary to sustain life. So too might the response to COVID-19 be seen as breathtaking. Besides the introduction, almost overnight, of extraordinary changes to our daily existence - notably practices of isolation, paradoxically consistent with the necessity for collectively thwarting COVID-19's communicability - science is also altering apace. New collaborations are rapidly arising across a globally dispersed bioscientific field, aimed at devising and testing innovative therapeutics and vaccines. It would be easy to attribute these myriad changes to the virility of the virus itself and, also, assume science will be our saviour ... But as much as science might be our ally, it is not immune to question. The first principle of science is that existence is composed of independent physical objects and events, of 'things' essentially isolated and that interact with finite consequences. Each event makes its difference in a linear succession. Perhaps with a residue, but as if without immanent connection and creativity for what becomes. Breath in this schema is imagined as essential but, nonetheless, no more than an exchange of elements between isolated beings, elements of plant and animate life (including viral agents) and what they are thought to 'contain' or unleash. (Rosegarten 2020: 342)

As Fergie and colleagues demonstrate, breath is ever so much more. Like Fergie and colleagues, Rosegarten wonders after the 'communicability' of breath and desires a theorising of it beyond biological sustenance. Such wondering after breath takes us beyond the transmission of a virus and into a social world in which social connection and disconnection become as important for understanding crises and responses to them as do matters biological.

It is productive, too, to think, as Francesca Messineo does, of the ways in which the virus that so many 
analysts understand as forcing us apart might draw us together. This, says Messineo, might be thought of as a kind of organism work, in which we take the chance the virus has presented for creating a political, social and cultural nucleus. Such considerations are, truly, macro-cosmological, and can be accessed in their fullness by means of particular channels like, for example, money. Attending often to the ways in which a focus on money (and its absence) lets us glimpse what might be possible, Messineo asks us to consider what negotiations might come available with the virus 'if we embrace an inclusive approach towards animals, vegetables and all the non-human agents that populate our living environment'. Money arises here not as inert object, but instead as something with its own consistency with which we must negotiate - just as we must negotiate with the virus itself, which has its own capacity to impact the condition of our own being.

The notion that the virus itself might have agency, that it might 'be', returns us to the secret world of the microbial and the conditions under which it is revealed to us. Whether in and through scientific discovery and advancement, or via the unexpected arrival of a virus as successful as sourdough yeast, the contributors to this section of this issue stay with the notion that conditions under which knowledge of matters microbial arise are at least as important as understanding the microbes themselves. They each refuse to stay with the microbial, and instead trace networks that spin the microscopic into multiple provocations for thinking, acting and surviving.

\section{Bodies}

The final two sections, entitled 'Bodies (in Danger): Breathing, Coughing, Spitting and Touching' and 'Bodies (in Leisure): Singing, Dancing and Holidaying', consider how our intimate relationships with our own and other bodies are transforming as a result of the pandemic. However, and in contrast to 'Beginnings', the focus is very much upon the lastingness, or otherwise, of those transformations.

In this respect, and on the basis of long-term research, Ellen Block draws conclusions suggesting that the doctor-patient intimacies witnessed by Colas in the thick of the pandemic's initial outbreak in the United States may give way to something else, a 'habitus of infection' as she describes it. This consists of new embodied dispositions and forms of self-consciousness affording doctors protection from infected patients. It manifests itself in multiple new mundane practices such as the clustering of tasks in order to reduce the frequency of visits into a patient's room. However, cumulatively these amount to a fundamental reorientation of the spatio-temporal operation and treatment of bodies within clinical settings. Crucially, for our purposes these portend a fundamental transformation of patient-doctor intimacies, which now take place less via skin-to-skin touch, eye contact and facial expression and more, in albeit impoverished ways, through the likes of communication technologies.

The habitus of infection that Block describes is a reaction to heightened risk but it is also, perhaps, a modern (and hospitals are quintessentially modern institutions) concern with the boundedness of bodies (Dawson 2002). Indeed, that concern is even echoed in pathology nomenclature. For example, incontinence, characterised by incapacity to control the boundaries of the body, is derived from the verb to 'uncontain' (Dawson 2002). Furthermore, and concomitantly, the modern concern with boundedness extends to modern concerns with body and the self being individual (Bauman 1992), autonomous (Becker 1995) and subject to self-control (Elias 1985). Picking-up from Anthony Giddens' (1992) work on modernity, individualisation and intimacy, Jonathan Skinner's article is, in many ways, an autobiographical reflection on the development of 'his' own modern body and selfhood in lockdown. Much of his time was spent practising his favourite leisure pursuits, tennis and tango, only now in socially distant modes. He describes how these occasioned opportunities for reflecting on selfhood and, in the midst of living with the uncertainties wrought by COVID-19, for coping with isolation, maintaining a healthy body and mind, and, especially for retaining threatened intimacies in new ways.

Contrastingly, Cynthia Sear's (and others) reflections on the future of the body post-COVID-19 are less hopeful. For Sear, in COVID-19 the myth of the bounded body is replaced by heightened body porosity-awareness. This gives rise to new forms of 'violence', such as aggressive spitting in which the fluids that the body emits become weaponised, new forms of 'bodily performance' designed to persuade others of our non-porosity, and new forms of 'disgust' towards others who fail to display such capacities. This amounts to a kind of porosity politics which is characterised, above all, by the emergence of new forms of 'social distinction for some and abjection' for others. Indeed, the question of the relationship between COVID-19, bodily porosity and intimacy, social distinction and, especially, abjection frames several of the articles that follow. 
Andreas Streinzer and colleagues highlight how the pandemic has made apparent a 'double standard' of intimacies. Their focus is on a technology called the 'cuddle curtain' that was developed for use in nursing homes in Switzerland to enable residents to engage in much needed physical contact with friends and relatives without, however, having to expose vulnerable older residents to the dangers of direct bodily contact. Relatedly, as an aside, in an article in Volume 22, Issue 3, Bob Simpson remarks wittily about similar but more advanced technologies - 'No doubt', he states, 'someone in the R\&D department of an ICT company is at this moment trying to figure out how to deliver a haptic hug via a virtual reality headset and gloves'. However, Streinzer and colleagues compare the cuddle curtain to the like technology of body fluid barriers most commonly used by sex workers. While the use of the former technology was at least celebrated in the context of the nursing homes, the idea of using the latter technology was certainly not. This points to taboo surrounding intimate contact between older people, against the permissibility of intimate contact between older people and their families.

The relationship between COVID-19, bodily porosity and intimacy, and social distinction, how they may play out as broader moral panics (Cohen 1972), and the stigmatisation of body boundary transgressor groups are the focus of the articles by Hazel Andrews and Bryan Lim. Andrews considers the kinds of tourists, in search of intimacy, whose licentious behaviours have rendered places like the Spanish holiday town of Magaluf as 'Shagaluf'. And Bryan Lim reflects upon the gay men with whom he socialises in London, who, despite guidelines on social distancing, continue to meet up and congregate so as to engage in a myriad of both sexual and non-sexual practices.

In the current moral panic surrounding COVID-19, such groups might be rendered as 'covidiots', surely a term that will make its way into dictionaries of modern English. However, and with oblique reference to the modern condition, Lim writes:

There is something peculiar about our current situation, in that, despite the absence of a vaccine, we continue full steam ahead as though COVID-19 will eventually be 'vaccined away'. Is this a show of human resilience and confidence that we will conquer the virus in due course? Or is it, as Illich argued, a symptom of an impoverished and inadequate art of suffering such that managing COVID-19 out of existence is the only way we know how to live with it?
In this way, both Lim and, albeit indirectly, Andrews call into question the stigma. Rather, Andrews argues, 'the pandemic is not the first time that tourism has been highlighted as a harbinger of adjustments to intimacy' that may be required by COVID-19's continuity. And, Lim points out, gay men have a track record from which we might learn, having developed the kinds of same safer-sex methods (presumably in the context of HIV) that would later become endorsed by health-related organisations. Valuably, gay men, and perhaps tourists too, remind us, as Lim puts it, 'that there are many ways to live with COVID-19 beyond social distancing'.

If COVID-19-related awareness of the porous body threatens, as Sear seems to hint, the future of the modernity project (see also Oliver 1999), then Michael Ulfstjerne's article demonstrates how in other ways, and against the kinds of social fragmentations illuminated by Sear, Andrews and Lim, the porous body may solidify one of modernity's hallmark achievements, the making of the nation (see also Dawson 2018; Kapferer 1993; and Messineo in this issue). No aerosol has greater speed and reach than that emitted by the singing voice. Ulfstjerne informs us that during lockdown fully one-fifth of the population of Denmark engaged in collective singing online ... surely a kind of virtual comingling of breath and bodies. Brilliantly evocative, the article conveys simultaneously the author's sense of unease at getting caught up himself in what amounted to the revival of a highly national (and nationalist) vernacular singing tradition whilst being moved to tears by the songs. What this amounts to is, as Ulfstjerne pithily describes it, a 'sonic comradery' and 'somatic building blocks for imagined communities' or, to put it another way, perhaps a body-based national intimacy occasioned in this instance by COVID-19.

Andrew Dawson is Professor and Chair of Anthropology at the University of Melbourne. An ethnographer of human mobilities, he has conducted large-scale research projects in Australia, Bosnia and Herzegovina, England and Ireland.

E-mail: dawsona@unimelb.edu.au

Simone Dennis is Head of School, School of Archaeology and Anthropology, at the Australian National University. Her research interests coalesce around phenomenologically informed anthropological theories of embodiment, the senses and power. She has explored these interests in a range of ethnographic contexts, including policing, animal-human interactions in science laboratories, and licit substance use. 
She is best known for her work on tobacco use and her critical assessments of anthropology's operations in the public arena.

E-mail: simone.dennis@anu.edu.au

\section{References}

Anderson, B. (2006), Imagined Communities: Reflections on the Origins and Spread of Nationalism (London: Verso).

Bauman, Z. (1992), Mortality, Immortality and Other Life Strategies (Cambridge: Polity Press).

Becker, A. E. (1995), Body, Self and Society (Philadelphia: University of Pennsylvania Press).

Cohen, S. [1972] (2011]), Folk Devils and Moral Panics: The Creation of Mods and Rockers (London: Taylor and Francis).

Dawson, A. (2002), 'The Mining Community and the Ageing Body: Towards a Phenomenology of Community?' in Realizing Community: Concepts, Social relationships and Sentiments, (ed.) V. Amit (New York: Routledge), 21-37.

Dawson, A. (2018), 'Ageing and Dying Radically', Anthropology in Action: Journal for Applied Anthropology in Policy and Practice 25, no. 3: 23-33, doi:10.3167/ aia.2018.250303.

Elias, N. (1985), The Loneliness of Dying (Oxford: Basil Blackwell).

Foucault, M. [1995] (1975), Discipline and Punish: The Birth of the Prison (London, Vintage Books).

Giddens, A. (1992), The Transformation of Intimacy: Sexuality, Love and Eroticism in Modern Societies (Cambridge: Polity Press).

Goodwin-Hawkins, B., and A. Dawson, (2018), 'Life's End: Ethnographic Perspectives', Death Studies 42, no. 5: 269-274, doi:10.1080/07481187.2017.1396394.

Kapferer, B. (1993), Nationalist Ideology and a Comparative Anthropology (Colombo: Studies in Society and Culture).
Kozinets, V. K. (1998), ‘On Netnography: Initial Reflections on Consumer Research Investigations of $\mathrm{Cy}$ berculture', Advances in Consumer Research 25, no. 1: 366-371, https://www.acrwebsite.org/volumes/8180/ volumes/v25/NA-25.

Lakoff, G., and M. Johnson (1980), Metaphors We Live By (Chicago: University of Chicago Press).

Liberman, J. (2020), 'What Could Our Post-COVID “New Normal” Look Like? Pursuit, 9 April, https:// pursuit.unimelb.edu.au/articles/what-could-ourpost-covid-new-normal-look-like.

MacDonald, J. (2020), 'Australia and China Trade Blows Over Calls for a Coronavirus Inquiry', The Diplomat, 8 May, https://thediplomat.com/2020/05/ australia-and-china-trade-blows-over-calls-for-acoronavirus-inquiry/.

McKeever, V. (2020), 'The Coronavirus Is Expected to Have Cost 400 Million Jobs in the Second Quarter, UN Labour Agency Estimates', CNBC, 30 June, https://www.cnbc.com/2020/06/30/coronavirusexpected-to-cost-400-million-jobs-in-the-secondquarter.html.

Oliver, C. (1999), 'Ordering the Disorderly', Education and Ageing 14, no. 2: 171-202.

Rollins, M. F., S. Chowdhury, J. Carter, S. M. Golden, H. M. Miettinen, A. Santiago-Frangos ... and B. Wiedenheft (2019), 'Structure Reveals a Mechanism of CRISPR-RNA-Guided Nuclease Recruitment and Anti-CRISPR Viral Mimicry', Molecular Cell 74, no. 1: 132-142, doi:10.1016/j.molcel.2019.02.001.

Rosegarten, M. (2020), 'The Challenge of Breath: Toward an 'After' COVID-19', Social Anthropology 28, no. 2: 342-343, doi:10.1111/1469-8676.12806.

Van Mannen, J. [1988] (2011), Tales of the Field: On Writing Ethnography (Chicago: University of Chicago Press).

World Health Organization (WHO). (2020), Coronavirus Disease (COVID-19) Situation Report - 87, 30 April, https://www.who.int/docs/default-source/ coronaviruse/situation-reports/20200416-sitrep-87covid-19.pdf?sfvrsn=9523115a_2 